\title{
Healthy older adults' perceptions of their memory functioning and use of mnemonics
}

\author{
EUGENE A. LOVELACE \\ Alfred University, Alfred, New York \\ and \\ PAUL T. TWOHIG \\ U.S. Army Research Institute, Alexandria, Virginia
}

\begin{abstract}
Interview data were gathered from a purposive sample of $\mathbf{4 0}$ healthy, articulate older adults (54 to 85 years old, median $=68$ years) concerning the events causing memory problems in their everyday activities, the extent to which they felt they had experienced any change in memory as they grew older, and the sorts of memory aids they employed. The examples of forgetting they provided included both retrospective memory failures (the most common and most irritating being the inability to recall someone's name) and prospective memory failures (e.g., forgetting to get or do a certain thing while out shopping). For each specific type of memory failure, the modal response was of no change with aging, yet $70 \%$ of participants reported an increase in memory failure for one or more items. The memory aids most widely reported involved external mnemonics such as writing notes and placing things in conspicuous places so as not to forget them. The pattern of use of mnemonics parallels other data in the literature for younger adults.
\end{abstract}

The present paper is concerned with the subjective impressions of healthy, active elderly individuals regarding changes in their memory functioning as a result of aging. It also examines mnemonic strategies they report employing to deal with the memory demands of daily activities.

Since self-report measures of memory functioning have not been shown to be consistently related to actual memory performance on controlled tests, some researchers may be inclined to minimize the value of measuring individuals' perceptions of their memory functioning. Others, however, have argued that the nature of subjective impressions of change in memory functioning is an interesting subject in its own right: "self-perceptions can have a remarkable impact on performance ... especially ... in the realm of memory abilities" (Thompson, 1980, p. 372), and "beliefs that people have about their memory abilities are of interest, not just because they may provide information about actual memory abilities, but because their beliefs, regardless of accuracy, affect behavior"' (Chaffin \& Herrmann, 1983, p. 17).

There is evidence that many adults do perceive their memory functions to be declining as they grow older, even in those cases where pathology has been essentially ruled out. Several such studies are discussed below in conjunction with analyses of the present data. One such study examined aged individuals who were healthy, well educated, and financially secure. A major thrust of that article was

This study was conducted while both authors were at the University of Virginia. Portions of these data were reported at meetings of the Eastern Psychological Association in 1983 and the American Psychological Association in 1984. Reprint requests may be addressed to E. Lovelace, P.O. Box 807, Alfred, NY 14802. to demonstrate that "the negative stereotype of the aged vanishes when the old are educated, affluent and "healthy'" (Hellebrandt, 1980, p. 404); it was still reported, however, that "one complaint was voiced unreservedly by many of the respondents and that was frustration caused by failures of memory" (Hellebrandt, 1980, p. 408).

Recent studies have used diaries, questionnaires, or structured interviews to learn about everyday memory functioning (e.g., Cavanaugh, Grady, \& Perlmutter, 1983; Crovitz \& Daniel, 1984; Harris, 1980). In the present research, healthy, well-functioning older adults were interviewed concerning their perceptions of their own memory performance. Data were gathered relevant to three broad questions: (1) What sorts of things do older adults report as presenting problems with respect to their memory functioning in everyday activities? (2) Do they feel they have experienced change in such forgetting as they have grown older? (3) What sorts of strategies or mnemonics do they report using to help them remember?

\section{METHOD}

\section{Participants}

We selected a purposive sample of healthy older adults with good verbal skills. Forty active, well-educated members of the community in Charlottesville, VA were interviewed by a female research assistant. Their ages ranged from 54 to 85 years (median $=68$ years). All had high school diplomas; $60 \%$ had a B.A. or equivalent degree. By self report, 9 participants viewed their health as "fair," and the remainder as "good" or "excellent."

\section{Procedure}

Interviews were conducted at a time and location convenient for the participants, typically in their own homes. The interview began with open-ended questions, which became progressively more structured. There followed a series of specific questions requiring forced-choice 
answers as to (1) the subjective frequency with which certain memory events were experienced and (2) whether the frequency had changed with age. Seven of these questions dealt with specific kinds of memory failure and 13 dealt with the use of memory aids. (The specific questions are described below as the results are presented.)

It was stressed that the participants were to answer each question with respect to their own experience, not what they felt might be true in general for others their age. Frequency judgments were made on a 7-point scale requiring judgments of absolute frequency (Harris, 1980); scale values were never, 1 or 2 times in the last 6 months, 1 or 2 times in the last 4 weeks, 1 or 2 times in the last 2 weeks (about weekly), 3 to 5 times in the last 2 weeks, 6 to 10 times in the last 2 weeks (about every other day), and more than 10 times in the last 2 weeks (almost daily). As to change with age, the participant indicated that the event now had occurred more often, less often, or that there had been no change. Responses to the open-ended questions were tape-recorded for later analysis.

\section{RESULTS AND DISCUSSION}

First the responses to the open-ended questions will be summarized, then those for the forced-choice questions. For the open-ended questions, the percentage of the $\mathbf{4 0}$ participants who gave a particular response is reported. (An occasional response was not appropriate to the question; in those cases, we have reported the percentage of the appropriate and scorable responses; 37 or more were appropriate in all cases.)

\section{Open-Ended Questions}

The interviewer began by stating that most people experience two types of forgetting: (1) inability to recall something that they once knew, and (2) forgetting to do something they intended to do. All participants acknowledged that they had had such experiences, and were asked to give examples. For the first type-retrospective memory failures-the greatest number $(60 \%)$ reported the inability to recall someone's name. This is consistent with the data of Cavanaugh et al. (1983) for older adults, as well as with those of Crovitz and Daniel (1984) for college students. Another $20 \%$ gave an example of not remembering where they had put something.

The examples of prospective memory failuresforgetting to do something one intended to do-showed much less commonality in the responses. The two most frequent examples concerned failure to get (do) a certain thing on a shopping trip (12\%) and forgetting what they had come into a room to do (10\%).

When asked whether they thought that these two types of forgetting happened more or less often as they grew older, $62 \%$ said more often, $30 \%$ felt there had been no change, and the remaining $8 \%$ said they did not know. The finding that the majority did perceive an age-related memory loss is consistent with other recent studies (Hellebrandt, 1980; Hultsch, Hertzog, \& Dixon, 1987; Sunderland, Watts, Baddeley, \& Harris, 1986). No clear relationship was found between age and perceived increase in forgetting, although several studies have found the perceived decline to be greater for older adults (Dixon \& Hultsch, 1983; Perlmutter, 1978; Williams, Denney, \& Schadler, 1983).
When asked what sorts of memory failures were most annoying, embarrassing, or irritating, $55 \%$ cited failure to recall someone's name, $15 \%$ described failing to do something they had planned to do, $12 \%$ said not knowing where they had put something, and $7 \%$ mentioned losing their train of thought in conversation or being unable to think of a word they wanted to use.

Before being specifically queried about mnemonic strategies, $25 \%$ of the participants spontaneously indicated that they wrote things down to help them remember (notes to themselves, shopping lists, etc.). The participants next were asked, "Do you have any methods that you use to help you remember things that you are afraid you will forget?' Sixty-two percent indicated that they wrote things down, and $27 \%$ described trying to form associations between things they wished to remember. Twenty-five percent said they had no methods to try to assure remembering something. (Percentages here total more than 100\% since some participants gave more than one answer.)

Questions were also asked about the participants' memory for routine events (e.g., taking one's pills), about forgetting the intention of an act (e.g., why one is doing something), and whether memory lapses ever pose problems for them in conversation with, or in writing to, another person. As expected, the majority reported experiencing each of these three sorts of memory problems (78\%, $88 \%$, and $61 \%$, respectively). The majority $(63 \%)$ of those who said they sometimes forgot the intention of an act reported that this variety of memory problem had increased as they grew older, whereas $37 \%$ felt there had been no change. Similarly, of those who reported forgetting a word they wanted to use or losing their train of thought during conversation, $65 \%$ felt this had increased with age, whereas $35 \%$ felt there had been no change. Note that those reporting a perceived change in either frequency of forgetting intended actions or elements in conversation all reported an increase in forgetting. However, with respect to "routine events such as whether you have locked the door, or taken your pills, or where you put your keys,"' only $18 \%$ felt this showed any increase with age. For some participants (18\%), forgetting of routine things was reported to have occurred for them rarely, if ever, at any age. An additional $63 \%$ reported that they did forget routine events, but felt there had been no increase. Thus, more than $80 \%$ of the participants saw no decline in their memory for routine events as they grew older. In light of the general impression of memory decline, we found this result quite interesting. When asked for methods that they used to remember routine things, the most common reply was that no method was used (34\%); of those who did describe a strategy, the most common response was to depend on someone else $(14 \%)$-in every case, the participant's spouse. This perception of stability in memory for routine events may not be accurate; a recent diary study of frequency of reported memory failures and use of memory aids found a greater number of entries of memory failures for routine events for older than for young adults (Cavanaugh et al., 1983). 
Table 1

Replies to Questions on Forced-Choice Memory Events

\begin{tabular}{|c|c|c|c|c|c|}
\hline \multirow[b]{2}{*}{ Type } & \multicolumn{2}{|c|}{ Frequency } & \multicolumn{2}{|c|}{ Change With Age } & \multirow[b]{2}{*}{$\mathbf{P}$} \\
\hline & Ever & Weekly & Increase & Decrease & \\
\hline \multicolumn{6}{|c|}{ Percentage of Subjects Reporting Memory Failures } \\
\hline Word in conversation & 95 & 42 & 42 & 0 & .01 \\
\hline Intention of act & 95 & 20 & 40 & 2 & .01 \\
\hline Bring up point (conversation) & 90 & 15 & 22 & 2 & .05 \\
\hline Uncertain task was done & 80 & 15 & 20 & 0 & .01 \\
\hline To do routine act & 78 & 12 & 15 & 7 & n.s. \\
\hline Lose train of thought & 73 & 10 & 15 & 0 & .05 \\
\hline Fail to mail something & 48 & 2 & 5 & 2 & n.s. \\
\hline \multicolumn{6}{|c|}{ Percentage Reporting Use of Various Mnemonics } \\
\hline \multicolumn{6}{|l|}{ External } \\
\hline Calendar & 95 & 85 & 25 & 2 & .05 \\
\hline Put in noticeable place & 90 & 65 & 15 & 8 & n.s. \\
\hline Make shopping list & 90 & 48 & 10 & 2 & n.s. \\
\hline Written memos to self & 55 & 30 & 10 & 2 & n.s. \\
\hline Cooking timer & 45 & 30 & 5 & 8 & n.s. \\
\hline Ask someone to remind & 73 & 23 & 20 & 2 & n.s. \\
\hline \multicolumn{6}{|l|}{ Internal } \\
\hline Mental retracing & 90 & 12 & 18 & 0 & n.s. \\
\hline Get visual image & 65 & 10 & 8 & 0 & n.s. \\
\hline Go through alphabet & 62 & 15 & 12 & 5 & n.s. \\
\hline Make up rhymes & 58 & 2 & 5 & 5 & n.s. \\
\hline No. items shopping for & 33 & 8 & 0 & 0 & n.s. \\
\hline Acronym of first letters & 33 & 5 & 2 & 2 & n.s. \\
\hline Make up story & 5 & 2 & 2 & 0 & n.s. \\
\hline
\end{tabular}

\section{Forced-Choice Questions}

The forced-choice set of questions concerning specific memory events were of two types: some dealt with the subjective frequency of certain types of memory failure; the others dealt with judged frequency of use of certain mnemonics. Table 1 provides summaries of the responses to those items and the extent to which that memory event was perceived to have changed with aging. The table lists kinds of memory failure (top portion) and kinds of mnemonics (bottom portion). Presented are the percentage of participants who reported ever experiencing that event (combining all frequency categories except " "never"'), the percentage experiencing the event "about weekly" or more often (top four frequency categories), and the percentage reporting perceived age-related increases or decreases in frequency of the event. The last column indicates the probabilities associated with sign tests of whether reports of increased and decreased frequency are equally likely.

Kind of memory failure. The combined percentages reporting increased and decreased frequency of a particular kind of memory failure (Table 1 , top) were consistently less than half, ranging from $7 \%$ to $42 \%$. Thus, for each type of failure, the majority of the participants perceived no change in their memory functioning with aging. For some events, however, nearly half the participants did report perceiving change, and $70 \%$ reported an increase in memory failures on one or more of the items.

For the data in the top portion of Table 1, there were significantly more individuals reporting an increase than a decrease with aging in every case but two: failing to mail something, which had a low frequency overall, making the test insensitive, and failure to remember to do something routine. The two events which were highest in frequency, and which showed a very substantial age-related increase, were being "unable to think of a word that you want to use in a conversation" and "forgetting what you were intending to do, such as why you came into a room, or what else you were going to do when you went out shopping." (It must be noted that there was no forced-choice item concerning the forgetting of names, the memory failure most frequently reported in the open-ended questions.)

Two other significant changes also relate to conversation: "At the end of a conversation, realize that you forgot to bring up some point or question that you had intended to," and "Forgot what you were planning to say, that is, 'losing your train of thought' while talking with someone." The remaining significant item read: "Being uncertain about whether or not you have done something."

Use of memory aids. Analyses of reported changes in frequency of use of specific mnemonics (Table 1, bottom) showed a significant increase only in the use of calendars to aid memory, although changes for 8 of the 12 remaining mnemonics were in the direction of increased frequency of use. When the mnemonic strategies are separated into those that are external and those that are internal (see column labeled "Type"), it is clear that the participants reported using the external mnemonics much more frequently than internal ones. This confirms similar findings by Intons-Peterson and Fournier (1986) for college students, and by Harris (1980, second study), whose participants were housewives from a study panel with a mean age of 46 years. In fact, the rankings of the frequency of use of these mnemonics as reported by the 
present participants and Harris's panel of housewives are nearly identical (Spearman correlation $=.94$ with ranking based on proportion reporting using the mnemonic more than once a week).

The pattern of the use of internal mnemonics is also similar to that reported by Harris (1980) in another respect. Our subjects were more likely to use retrieval mnemonics, which are only invoked when something is forgotten, than encoding mnemonics, which are constructed during initial encoding and storage of the experience. For example, going through the letters of the alphabet to cue a forgotten name or mentally retracing one's actions of that day to try to remember when one did something are retrieval mnemonics, whereas making up an acronym or a story to help one remember at a future time are encoding mnemonics. The major disadvantage of encoding mnemonics is that they often require considerable cognitive effort at a time when it is uncertain whether they will be needed in that particular case. It appears that people are more likely to use the easier route, to see if forgetting occurs, and then use a retrieval mnemonic if they find it necessary.

The preference for external mnemonics such as written lists is understandable since they should provide maximum likelihood of success with a minimum of cognitive effort. It should be noted, however, that all of the external mnemonics are encoding mnemonics-precautions taken in advance to preclude problems of forgetting. Also note that they are employed almost exclusively to prevent prospective memory failures (forgetting to do something intended), whereas the internal mnemonics are primarily aimed at reducing retrospective memory failures (losing the "content" of a memory).

\section{Memory and Daily Activities}

Overall, this sample of participants reported some increase in perceived memory failures, but no participant gave any evidence that the failures seriously hampered his or her daily functioning. Sunderland et al. (1986) similarly observed that "despite a universal belief among elderly adults that their memory had deteriorated with age, very few of them felt that they were at all handicapped by forgetfulness in everyday life"' (p. 376).

\section{CONCLUSIONS}

The findings of the present study, taken in conjunction with other recent studies cited above, permit the following conclusions about perceptions of memory functioning in late adulthood.

1. The majority of healthy, active elderly adults do perceive a decline in their memory function with aging.

2. Difficulty in retrieving names is arguably the memory failure of which people are most aware throughout life, and probably the one that shows the greatest subjective increase with aging. This failure is perhaps so salient in subjective assessments of memory function because of the social nature of the item sought and thus the embarrassment such failures can engender.

3. In general, people are aware of using external memory aids more frequently than internal memory aids. The relative frequencies of use of various mnemonics appear to be quite similar across ages. There does, however, appear to be some increase in the subjective frequency of using external aids, most notably writing notes to oneself and placing items where they will be seen to trigger memory.

4. The perceived increase in memory failures includes both retrospective and prospective memory. Examples of the former include being unable to think of a person's name or a word one wishes to use in conversation; examples of the latter include forgetting to do or buy something while out shopping, and losing one's train of thought or forgetting to make a point one intended during a conversation.

5. Despite the sorts of impressions of memory decline noted above, few healthy elderly adults feel that these changes pose serious problems for the effectiveness of their daily functioning. If these perceptions of memory decline are essentially veridical, an individual's memory functioning may have to decline substantially before it will begin to force notable changes in daily activities.

\section{REFERENCES}

Cavanaugh, J. C., Grady, J. G., \& Perlmutter, M. (1983). Forgetting and use of memory aids in 20 to 70 year olds everyday life. International Journal of Aging \& Human Development, 17, 113-122.

Chaffin, R., \& HerRmann, D. J. (1983). Self reports of memory abilities by old and young adults. Human Learning, 2, 17-28.

Crovitz, H. F., \& DANIEL, W. F. (1984). Measurements of everyday memory: Toward the prevention of forgetting. Bulletin of the Psychonomic Society, 22, 413-414.

Dixon, R. A., \& Hultsch, D. F. (1983). Structure and development of metamemory in adulthood. Journal of Gerontology, 38, 682-688.

HARRIS, J. E. (1980). Memory aids people use: Two interview studies. Memory \& Cognition, 8, 31-38.

HellebrandT, F. A. (1980). Aging among the advantaged: A new look at the stereotype of the elderly. Gerontologist, 20, 404-417.

Hultsch, D. F., Hertzog, C., \& Dixon, R. A. (1987). Age differences in metamemory: Resolving the inconsistencies. Canadian Journal of Psychology, 41, 193-208.

Intons-Peterson, M. J., \& FourNiER, J. (1986). External and internal memory aids: When and how often do we use them. Journal of Experimental Psychology: General, 115, 267-280.

Perlmutter, M. (1978). What is memory aging the aging of? Developmental Psychology, 14, 330-345.

Sunderland, A., Watts, K., Baddeley, A. D., \& Harris, J. E. (1986). Subjective memory assessment and test performance in elderly adults. Journal of Gerontology, 41, 376-384.

Thompson, L. W. (1980). Testing and mnemonic strategies. In L. W. Poon, J. L. Fozard, L. S. Cermak, D. Arenberg, \& L. W. Thompson (Eds.), New directions in memory and aging (pp. 367-377). Hillsdale, NJ: Erlbaum.

Williams, S. A., Denney, N. W., \& Schadler, M. (1983). Elderly adults' perception of their own cognitive development during the adult years. International Journal of Aging \& Human Development, 16, 147-158.

(Manuscript received August 31, 1989.) 